\title{
Underground Azelaic Acid-Conferred Resistance to Pseudomonas syringae in Arabidopsis
}

\author{
Nicolás M. Cecchini, ${ }^{1}$ Suruchi Roychoudhry, ${ }^{1}$ DeQuantarius J. Speed, ${ }^{1}$ Kevin Steffes, ${ }^{1}$ Arjun Tambe, ${ }^{1}$ \\ Kristin Zodrow, ${ }^{1}$ Katerina Konstantinoff, ${ }^{1}$ Ho Won Jung, ${ }^{2}$ Nancy L. Engle, ${ }^{3}$ Timothy J. Tschaplinski, ${ }^{3}$ \\ and Jean T. Greenberg ${ }^{1, \dagger}$ \\ ${ }^{1}$ Department of Molecular Genetics and Cell Biology, The University of Chicago, 929 East 57th Street GCIS 524W, Chicago, IL \\ 60637, U.S.A.; ${ }^{2}$ Department of Molecular Genetics, Dong-A University, 37 Nakdong-Daero 550beon-gil, Saha-gu, Busan 49315, \\ Korea; and ${ }^{3}$ Oak Ridge National Laboratory, PO Box 2008, Oak Ridge, TN 37831, U.S.A.
}

Accepted 24 August 2018.

Local interactions between individual plant organs and diverse microorganisms can lead to whole plant immunity via the mobilization of defense signals. One such signal is the plastid lipid-derived oxylipin azelaic acid (AZA). Arabidopsis lacking AZI1 or EARLI1, related lipid transfer family proteins, exhibit reduced AZA transport among leaves and cannot mount systemic immunity. AZA has been detected in roots as well as leaves. Therefore, the present study addresses the effects on plants of AZA application to roots. AZA but not the structurally related suberic acid inhibits root growth when directly in contact with roots. Treatment of roots with AZA also induces resistance to Pseudomonas syringae in aerial tissues. These effects of AZA on root growth and disease resistance depend, at least partially, on AZI1 and EARLI1. AZI1 in roots localizes to plastids, similar to its known location in leaves. Interestingly, kinases previously shown to modify AZI1 in vitro, MPK3 and MPK6, are also needed for AZA-induced root-growth inhibition and aboveground immunity. Finally, deuteriumlabeled AZA applied to the roots does not move to aerial

Nicolás M. Cecchini and Suruchi Roychoudhry contributed equally to this work.

Current address for Nicolás M. Cecchini: Centro de Investigaciones en Química Biológica de Córdoba, CIQUIBIC, CONICET, Departamento de Química Biológica-Ranwel Caputto, Facultad de Ciencias Químicas, Universidad Nacional de Córdoba, Haya de la Torre y Medina Allende, Ciudad Universitaria, Córdoba, X5000HUA, Argentina.

Current address for Suruchi Roychoudhry: Centre for Plant Sciences, University of Leeds, Leeds LS2 9JT, U.K.

${ }^{\dagger}$ Corresponding author: Jean T. Greenberg;

E-mail: jgreenbe@uchicago.edu

Funding: This research was supported by a National Science Foundation grant IOS1456904 to J. T. Greenberg. This research was also supported, in part, by the Genomic Science Program (Science Focus Area 'Plant-Microbe Interfaces'), United States Department of Energy, Office of Science, Biological and Environmental Research to Oak Ridge National Laboratory, which is managed by UT-Battelle, LLC, for the United States Department of Energy under contract number DE-AC05-00OR22725. D. J. Speed was supported by National Institute of General Medical Sciences grant T32 GM007183 and a predoctoral fellowship award from the Ford Foundation. N. M. Cecchini is a career investigator of CONICET (Argentina).

*The $\boldsymbol{e}$-Xtra logo stands for "electronic extra" and indicates that one supplementary figure is published online.

(c) 2019 The American Phytopathological Society tissues. Thus, AZA application to roots triggers systemic immunity through an AZI1/EARLI1/MPK3/MPK6-dependent pathway and AZA effects may involve one or more additional mobile signals.

Plants are capable of inducing systemic resistance programs after local recognition of microbe effectors or molecular patterns associated with them (Fu and Dong 2013; Spoel and Dong 2012). Systemic responses usually include the establishment of a long-lasting alert state or 'priming' of the defenses, which allows the plant to mount faster or stronger defense responses upon encountering new pathogens (Hilker et al. 2016; Martinez-Medina et al. 2016; Parker 2009). This recognition can happen in various plant tissues or organs such as leaves or roots and triggers different systemic defense programs (Pieterse et al. 2014). Infection of leaves with pathogens induces systemic acquired resistance (SAR) in distal aerial tissues (Cecchini et al. 2015; Fu and Dong 2013; Mishina and Zeier 2007), whereas root colonization by beneficial microbes promotes induced systemic resistance (ISR) in shoots (Pieterse et al. 1996). While SAR is dependent on the hormone salicylic acid (SA) defense pathway, ISR often relies on the jasmonic acid and ethylene signaling pathway (Pieterse et al. 2014). Although these defense programs do not share many components, the primed immunity triggered in aerial tissues is effective against an overlapping spectrum of invaders (Pieterse et al. 2014).

During the induction of systemic resistance, plants generate signals locally that can move to induce defenses in distal tissues (Chanda et al. 2011; Chaturvedi et al. 2012; Chen et al. 2018; Jung et al. 2009; Návarová et al. 2012; Park et al. 2007; Truman et al. 2007; Wittek et al. 2014). Among those signals, several are hydrophobic or lipid-related molecules, such as the oxylipin azelaic acid (AZA) (Chanda et al. 2011; Chaturvedi et al. 2012; Jung et al. 2009; Riedlmeier et al. 2017; Truman et al. 2007; Wittek et al. 2014). The exogenous application of AZA to aerial tissues induces a 'primed' state comparable to that seen after SAR induced by pathogen infection (Jung et al. 2009). AZI1 and EARLI1, two key proteins related to lipid transfer proteins (LTPs), are known components of the AZA signaling pathway (Cecchini et al. 2015; Jung et al. 2009). They are both needed for AZA priming induction and for the establishment of SAR. Furthermore, azil-1 and earli1-1 mutant plants have reduced movement of AZA from local to distal leaves. AZI1 is also needed for the action of one or more of the proposed systemic and interplant defense signals glycerol-3-phosphate, 
dehydroabietinal, and pinene-monoterpenes (Chaturvedi et al. 2012; Riedlmeier et al. 2017; Yu et al. 2013). In leaves, AZI1 and EARLI1 localize in the endoplasmic reticulum (ER), plasma membrane (PM), plasmodesmata (PD), and in the plastid outer envelope membrane (Cecchini et al. 2015), the site of generation of AZA and other signals (Chanda et al. 2011; Chaturvedi et al. 2012; Jung et al. 2009; Nandi et al. 2004; Park et al. 2007; Zoeller et al. 2012). It was suggested that this family of LTPs could form part of membrane contact site (MCS) complexes, allowing the movement of lipidic molecules through nonvesicular transport. MCSs between plastids, ER, and PD membranes play key roles in moving nonpolar priming signals to systemic tissues (Cecchini et al. 2015).

Several signals implicated in systemic resistance were proposed to be generated in leaves, but intriguingly, signals for systemic defense programs have yet to be identified in roots (Pieterse et al. 2014; Shah 2009). Among possible root signals that are related to various biotic or abiotic stresses are oxylipins or molecules related to oxylipin metabolism (Constantino et al. 2013; Fragoso et al. 2014; Ghanem et al. 2012; Grebner et al. 2013; León Morcillo et al. 2012; Nalam et al. 2013). Interestingly, many oxylipins are known to be generated in roots and several are related directly to defense against pathogens (Mukhtarova et al. 2011; Nalam et al. 2012; Vicente et al. 2012). In addition, some of these same oxylipins induce either root developmental growth arrest, morphological changes, or both, when applied to seedlings (Vellosillo et al. 2007). This suggests that oxylipins mediate a mechanistic link between root development and root defenses. Among the oxylipins that induce root architectural changes are AZA and the 9-oxo nonanoic acid (ONA) (Bouain et al. 2018; Vellosillo et al. 2007). Exogenous ONA induces systemic resistance and can generate AZA by oxidation (Wittek et al. 2014; Zoeller et al. 2012). Moreover, like AZA, ONA treatment of leaves induces disease resistance that depends on AZI1 (Wittek et al. 2014).

Although roots can produce AZA (Mukhtarova et al. 2011), it is not known whether AZA can move from roots-to-shoot or if the AZI1/EARLI1 LTP family proteins affect AZA-induced signaling after root application, as was observed in leaves (Cecchini et al. 2015). AZII and EARLII are expressed in roots (Bouain et al. 2018; Hruz et al. 2008). Furthermore, both LTPs are required for ISR (Cecchini et al. 2015). One possibility is that AZI1 and EARLI1 are needed for one or both normal AZA movement and systemic signaling triggered from roots as in leaves. Similarly, factors that modify these proteins may also be needed for root-mediated signaling. Candidate proteins for modifying AZI1 and EARLI1 are the regulatory kinases MPK3 and MPK6, which can phosphorylate AZI1 in vitro (Pitzschke et al. 2014). Moreover, MPK3 is also required for SAR development and, together with MPK6, for defense priming triggered by SA (Beckers et al. 2009).

Here, we analyzed if root-applied AZA can induce systemic disease resistance in Arabidopsis aerial tissues. Moreover, we also studied if AZA can move shootward from the root and if its action or signaling requires AZI1 and EARLI1 and their potential regulatory kinases. We show that AZA applied to roots induces both root morphological changes and systemic resistance; these phenotypes depend on AZI1 and EARLI1 as well as on MPK3 and MPK6. Furthermore, we show that AZI1 localization in roots resembles that seen in leaves. Interestingly, we did not see a detectable shootward movement of AZA from roots. Thus, although similar in its effect on disease resistance, AZA signaling from roots might have important differences compared with its mode of action in aerial tissues.

\section{RESULTS}

\section{AZA inhibition of root growth depends} on both AZI1 and EARLI1.

AZA can inhibit root growth in an AZI1-dependent manner (Bouain et al. 2018). Other oxylipins associated with defense against pathogens can also induce one or both root growth arrest and developmental changes (Vellosillo et al. 2007; Vicente et al. 2012). Therefore, we analyzed if the effect of AZA on the roots is specific and root-autonomous. To do this, aseptic wild-type Columbia-0 (WT Col-0) plants were grown on solid media supplemented with $40 \mu \mathrm{M}$ of AZA or corresponding mock conditions. As a control for specificity, we treated plants with $40 \mu \mathrm{M}$ suberic acid (C8), a molecule closely related in structure to AZA that cannot induce disease resistance (Jung et al. 2009). As shown in Figure 1A to C, seedlings grown on AZA plates showed a drastic inhibition of primary root growth accompanied by increased lateral root density compared with control plants. Developmental defects were not observed in aerial tissues (Fig. 1D). Importantly, AZA induced the same effects on plants in which shoot tissue was isolated from contact with AZA by using a glass coverslip (discussed below) (Fig. 2A and B). This indicates that the AZA effect is root-autonomous. $\mathrm{C} 8$ treatment did not induce any change in root architecture (Fig. 1A). Thus, specifically, AZA (and not a related molecule) is able to induce developmental changes in roots.

Since both LTPs AZI1 and EARLI1 are needed for AZAmediated systemic signaling (Cecchini et al. 2015; Jung et al. 2009; Yu et al. 2013), we next analyzed the effect of AZA on the roots of mutants lacking these factors. azi $1-1$ and earli1-1 mutant plants showed reduced responses to AZA in terms of root-growth inhibition as well as an increase in lateral root density when compared with WT Col-0 plants (Fig. 1B and C). This differential AZA response is well illustrated in Figure 1D. The results indicate that both AZI1 and EARLI1 are required for full AZA-mediated developmental responses in plant roots.

\section{Root-supplied AZA induces systemic resistance to Pseudomonas syringae.}

AZA treatment of a few lower leaves induces disease resistance in distal (systemic) leaves (Jung et al. 2009). Considering this, we examined if application of AZA to roots is also able to increase disease resistance in aerial tissues. To do this, adult WT Col-0 plant roots were treated with $1 \mathrm{mM}$ AZA (or mock) solution and leaves were infected with the Pseudomonas cannabina pv. alisalensis (formerly called P. syringae pv. maculicula [Bull et al. 2010]) strain PmaDG3 1 day later. The growth of PmaDG3 was quantified 3 days postinfection. We also treated plants with $1 \mathrm{mM} \mathrm{C} 8$ as control. As shown in Figure 3A, plants treated with AZA showed increased resistance to PmaDG3 compared with mock- or C8-treated plants. This indicates that AZA can induce systemic resistance when applied to the roots. Interestingly, root AZA treatment did not trigger systemic resistance to PmaDG3 in earli1-1 mutant plants, as compared with the mock treatment or WT Col-0 (Fig. 3B). However, azil-1 plants were still able to induce aerial defenses, albeit at a lower level than WT plants (Fig. 3B). These results indicate that EARLI1 is an essential factor for root-AZA systemic resistance establishment, while AZI1 is partially needed for full resistance.

\section{Root-supplied AZA does not prime pathogenesis-related protein 1 (PR1) or lipoxygenase (LOX2) in leaves.}

To determine if AZA treatment of roots can induce priming in leaf tissue through a similar signaling pathway as that in 
aerial tissue (Cecchini et al. 2015; Jung et al. 2009), we analyzed the levels and kinetics of PR1 accumulation in leaves. After roots were treated with AZA or a mock treatment, PR1 priming in leaves was analyzed at different times postinfection with PmaDG3 infection. AZA-treated WT plants did not show faster or higher induction of PR1 compared with mock treatment (Fig. 3C and D). Additionally, because previous studies found that $L O X 2$ in leaves is a priming target during ISR (Conrath et al. 2006; Pozo et al. 2008), we analyzed the induction kinetics of LOX2 after AZA root treatment and leaf infections. We used an antibody specific for LOX2 for these experiments (Fig. 3C, lower panel). As observed in Figure 3C and D, we did not detect priming of LOX2. In agreement with these data, azil-1 and earli1-1 mutant plants did not show PR1 or LOX2 priming (Fig. 3C and D).

These results indicate that root application of AZA induces systemic disease resistance without priming PR1 or LOX2 production in aerial tissues.
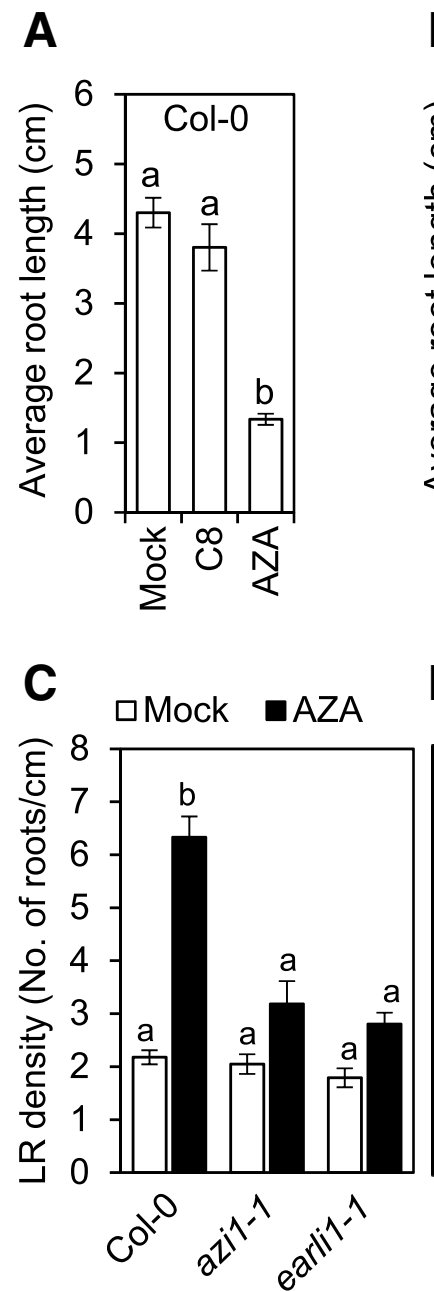

B

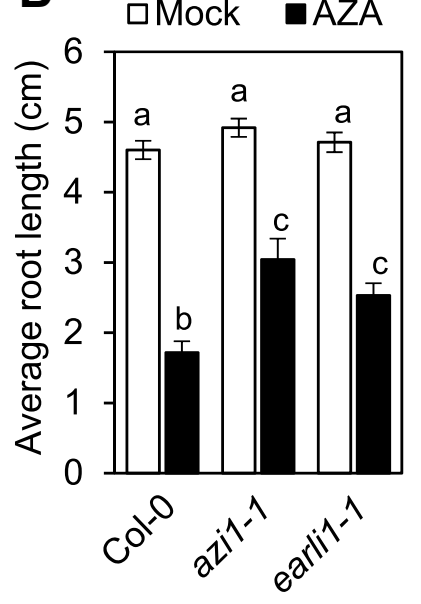

D

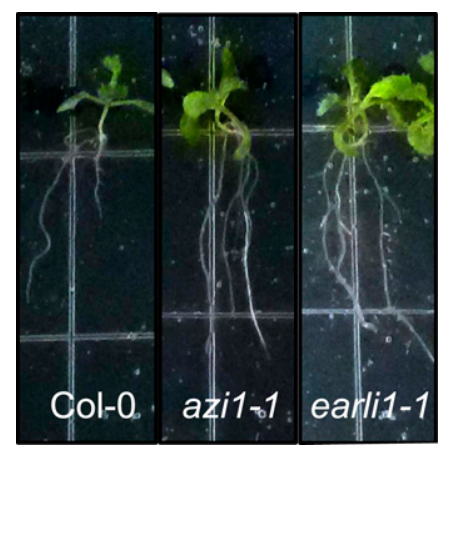

Fig. 1. Effect of azelaic acid (AZA) on seedling root growth. $\mathbf{A}$ and $\mathbf{B}$, Average root length and $\mathbf{C}$, lateral root (LR) density of 12-day-old seedlings grown on solid one-half Murashige and Skoog (MS) agar media supplemented with $40 \mu \mathrm{m}$ of AZA or suberic acid (C8) (in $5 \mathrm{mM}$ morpholineethane-sulfonic acid [MES] buffer, pH 5.7) and control MES (mock) in wild-type Columbia-0 (WT Col-0), azi1-1, and earli1-1 plants. The average root length or LR density \pm standard error from two (A) and four (B and C) independent experiments (with 10 to 12 biological replicates each) is shown. Different letters indicate statistically significant differences $(P<$ 0.01 , analysis of variance, post hoc Tukey's honestly significant difference test). D, Representative pictures of the seedlings analyzed in B and C, grown on the same plate.
MPK3 and MPK6 are needed for root responses to AZA and ISR.

MPK3 and possibly MPK6 can phosphorylate AZI1 in vitro (Pitzschke et al. 2014). Therefore, we analyzed if MPK3 and MPK6 have roles in the AZA-induced root developmental phenotype, systemic resistance induction, or both. As shown in Figure $4 \mathrm{~A}$ and $\mathrm{B}, \mathrm{AZA}$-induced root-growth inhibition was reduced in the mutants compared with WT Col-0 plants, while the increase in lateral root density disappeared. Moreover, both $m p k 3$ and mpk6 single mutants were unresponsive to AZA root treatment when analyzed for systemic resistance to PmaDG3 infection (Fig. 4C). These results indicate that MPK3 and MPK6 are required for AZA-mediated systemic defense induction from roots.

Since AZA signaling components AZI1 and EARLI1 are needed for normal ISR establishment (Cecchini et al. 2015), we also tested if MPK3 and MPK6 are implicated in this important systemic defense response. For this, we inoculated WT Col-0, $m p k 3$, and $m p k 6$ roots with $P$. fluorescens and, after 2 weeks, analyzed the growth of PmaDG3 after challenging distal leaves. Compared with WT plants, both mutants were completely ISR defective (Fig. 4D).

Taken together, these results indicate that MPK3 and MPK6 are important components for root-mediated systemic disease resistance induced by different stimuli.

\section{AZI1 likely localizes to the plastid outer envelope and other membranes in roots.}

In leaf tissue, AZI1 localizes to ER, PM, PD, and the plastid outer envelope, the site where AZA and other oxylipins are produced (Cecchini et al. 2015; Lim et al. 2016). To discern one or more possible AZI1 sites of action in roots, we examined its subcellular localization in this tissue in plants previously shown to express functional dexamethasone (dex)-inducible AZI1:

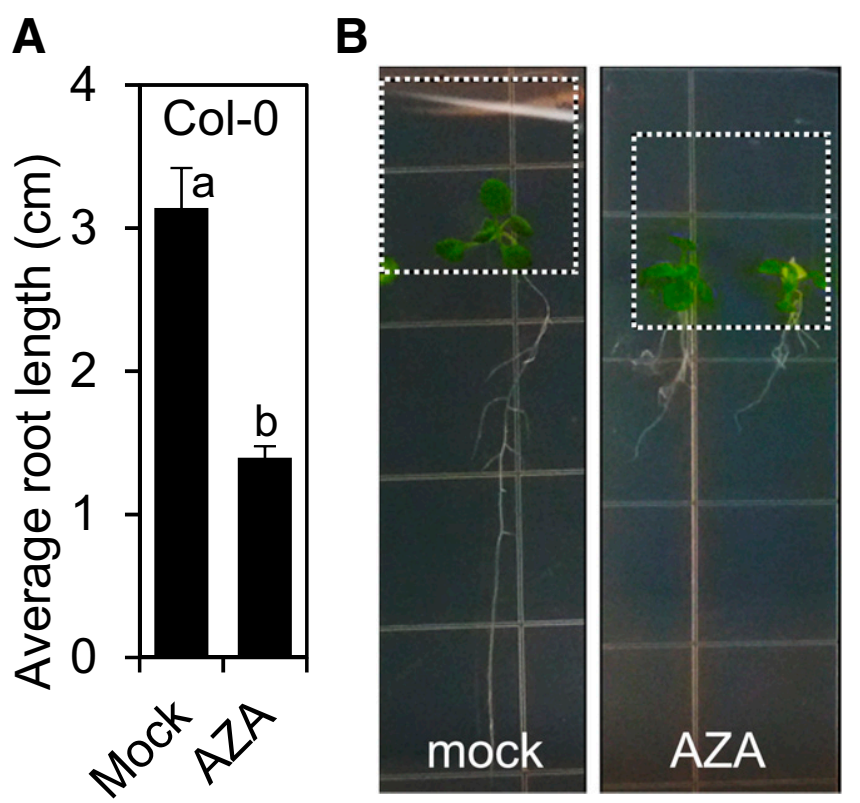

Fig. 2. The azelaic acid (AZA) effect on root growth is root autonomous. A, Average root length of 10-day-old wild-type Columbia-0 (Col-0) seedlings grown on solid one-half Murashige and Skoog agar media supplemented with $40 \mu \mathrm{m}$ AZA (in $5 \mathrm{mM}$ morpholineethane-sulfonic acid [MES] buffer, $\mathrm{pH}$ 5.7) or control MES (mock). Seedling aerial tissue was isolated from contact with media by using a sterile glass coverslip. The average root length \pm standard error from three independent experiments (each with 10 to 12 biological replicates) is shown. Different letters indicate statistically significant differences ( $P<0.01$, Student's $t$ test). B, Representative pictures of the seedlings analyzed for A. White dashed lines outline the area of tissue isolated from contact with media by a sterile glass coverslip. 
GFP (green fluorescent protein) (Cecchini et al. 2015). Roots expressing AZI1:GFP and stained with propidium iodine (PI) to visualize cell borders were analyzed by laser scanning confocal microscopy (Fig. 5A). GFP signals were evident at cell peripheries (near PI signals, likely at the PM, ER, or both) and at autofluorescent structures inferred to be small plastids. Closeup imaging revealed AZI1:GFP ring patterns that surrounded the small autofluorescent plastids (Fig. 5B). This fluorescence pattern resembles the AZI1 plastid outer envelope localization in leaves (Cecchini et al. 2015). To validate the plastid localization, roots of $\mathrm{F} 1$ plants resulting from a cross of the AZI1:GFP line to a line with the root-plastid marker RecAred (Haswell and Meyerowitz 2006) were analyzed. A pool of AZI1:GFP protein colocalized to plastids marked by RecAred (Fig. 5C and D). In the RecAred-expressing line, no GFP signals were detected, indicating there was no bleed-through of the RecAred signal to the GFP channel (Fig. 5E).

These results suggest that AZI1 has similar subcellular sites of action in roots and leaves.

\section{AZA is not transported from root to shoot.}

AZA moves from local leaves to systemic tissues in a manner that partially requires AZI1 and EARLI1 (Cecchini et al. 2015; Jung et al. 2009). One possibility is that AZA also moves from the roots to the shoot with AZI1 and EARLI1 playing roles in this movement. To test this hypothesis, we applied $1 \mathrm{mM}$ of deuterium-labeled AZA ( $\left.{ }^{2} \mathrm{H}-\mathrm{AZA}\right)$ to WT, azil-1, and earli1-1 seedling roots and quantified the amount of ${ }^{2} \mathrm{H}-\mathrm{AZA}$ in treated root and untreated leaf tissue after $24 \mathrm{~h}$. Although ${ }^{2} \mathrm{H}$-AZA was taken up, the ${ }^{2} \mathrm{H}$-AZA was not detectable in aerial tissues (Table 1). Compared with WT Col-0 plants, azil-1 and earli1-1 mutant plants did not show differences in the root uptake of ${ }^{2} \mathrm{H}-$ AZA. We also quantified the amount of unlabeled AZA present in the same samples. Table 1 shows that internal AZA was measured in roots and shoots, indicating that we were able to detect it in both tissues. We considered the possibility that AZA might cause increased ONA accumulation in leaves. While we were able to obtain a spectrum for synthetic ONA after derivatization (Supplementary Fig. S1), we were unable to detect ONA in our biological samples. Possibly ONA levels are below the limit of detection.

These data suggest that AZA is either unable to move from roots to distal aerial tissue when exogenously applied (or that

Fig. 3. Root-applied azelaic acid (AZA) specifically confers systemic disease resistance to Pseudomonas syringae. A, Growth of virulent bacteria PmaDG3 on wild-type Columbia-0 (WT Col-0) plants 3 days postinfection (optical density at $600 \mathrm{~nm}\left[\mathrm{OD}_{600}\right]=0.0003$ ). PmaDG3 was infiltrated in leaves 1 day after roots were treated with control $\mathrm{H}_{2} \mathrm{O}$ (mock) or $1 \mathrm{mM} \mathrm{C} 8$ or AZA (in $\mathrm{H}_{2} \mathrm{O}$ ). B, Growth of virulent bacteria PmaDG3 on WT Col-0, azil-1, and earli1-1 treated as in A. The average number of colony-forming units per leaf disc \pm standard error from two (A) or four (B) independent experiments (each one with eight biological replicates) is shown. Graph $y$ axes are in $\log _{10}$ scale. C, PR1 and LOX2 protein levels in WT Col-0 and azil-1 and earli1-1 total extracts at different times postinfiltration of PmaDG3 $\left(\mathrm{OD}_{600}=0.01\right)$, to test priming in plants previously treated as in B. The blots stained with Coomassie blue are presented to show loading. Similar results were observed in four independent experiments. Lower panel shows LOX2 (Arabidopsis LOX-C) (Agrisera AS07 258) antibody validation. LOX2 protein level in WT Col-0, lox2-1 (LOX2 mutant plant), CS3748 (LOX2 silenced line), and CS3749 (CS3748 control line) total protein extracts. Antibody was used at 1:25,000 dilution. The blots stained with Coomassie blue are presented to show loading. D, PR1 and LOX2 levels in $\mathrm{C}$ relative to the total protein content in each Coomassie blue membrane lane as quantified by densitometry. The average \pm standard error from four independent experiments are shown. Different letters indicate significant differences $(P<0.01$, analysis of variance, Tukey's honestly significant difference test). Plants were grown in peat pellets. the movement is very low) or AZA was transformed to an AZA derivative. This contrasts with the high mobility of AZA applied to leaves, which moved both to other leaves and roots (Cecchini et al. 2015).

\section{DISCUSSION}

Signals acting in plant underground tissues and capable of inducing aboveground systemic resistance are scarce. Intriguingly, the SAR signal AZA can be produced in stressed

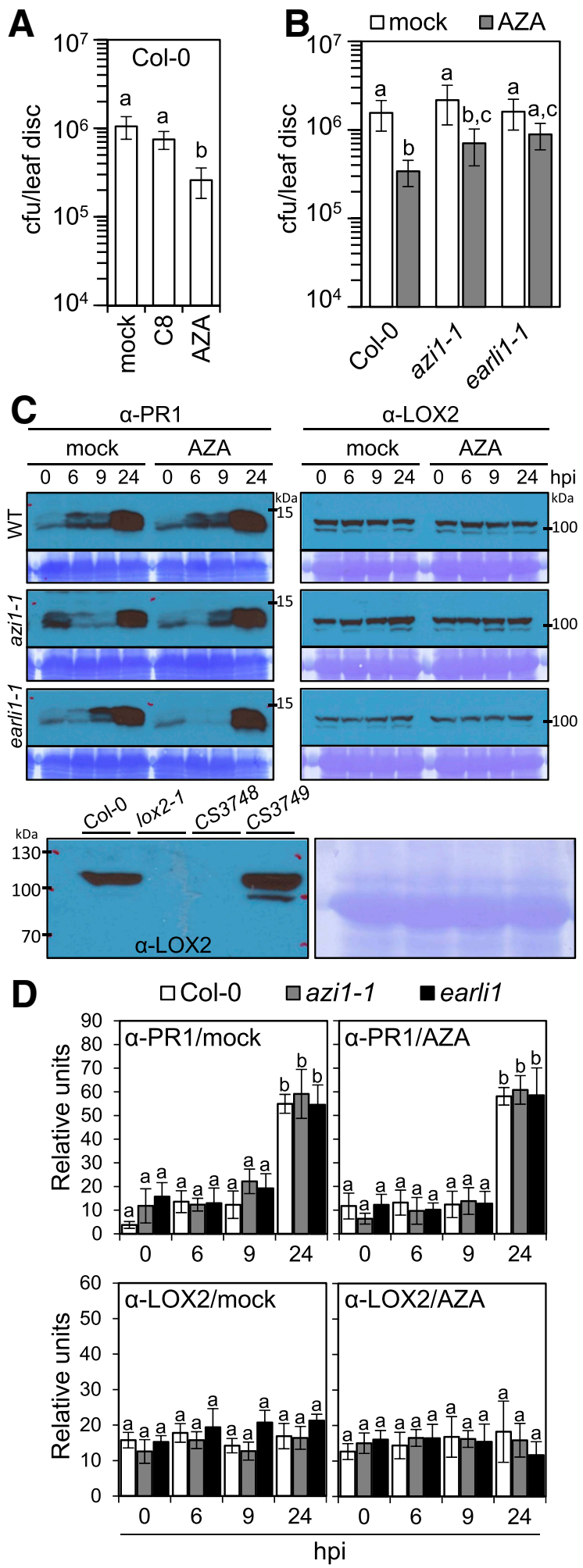


roots (Jung et al. 2009; Mukhtarova et al. 2011). Here, we showed that application of AZA to roots effectively triggers systemic disease resistance in leaves. The effects of rootapplied AZA depend on AZI1 and EARLI1, which are also needed for other systemic defense programs (e.g., SAR and ISR). Additionally, the possible regulators of AZI1, i.e., MPK3 and MPK6, are required for the root-mediated response to AZA and $P$. fluorescens (a potent inducer of ISR). Although common factors are needed for AZA disease resistance induction after application to leaves or roots, the effects of AZA on signaling may be tissue-specific. In particular, AZA applied to roots did not cause priming of defense markers usually associated with

A

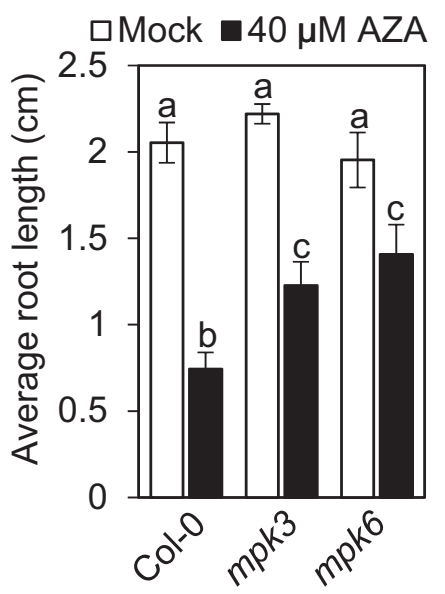

B
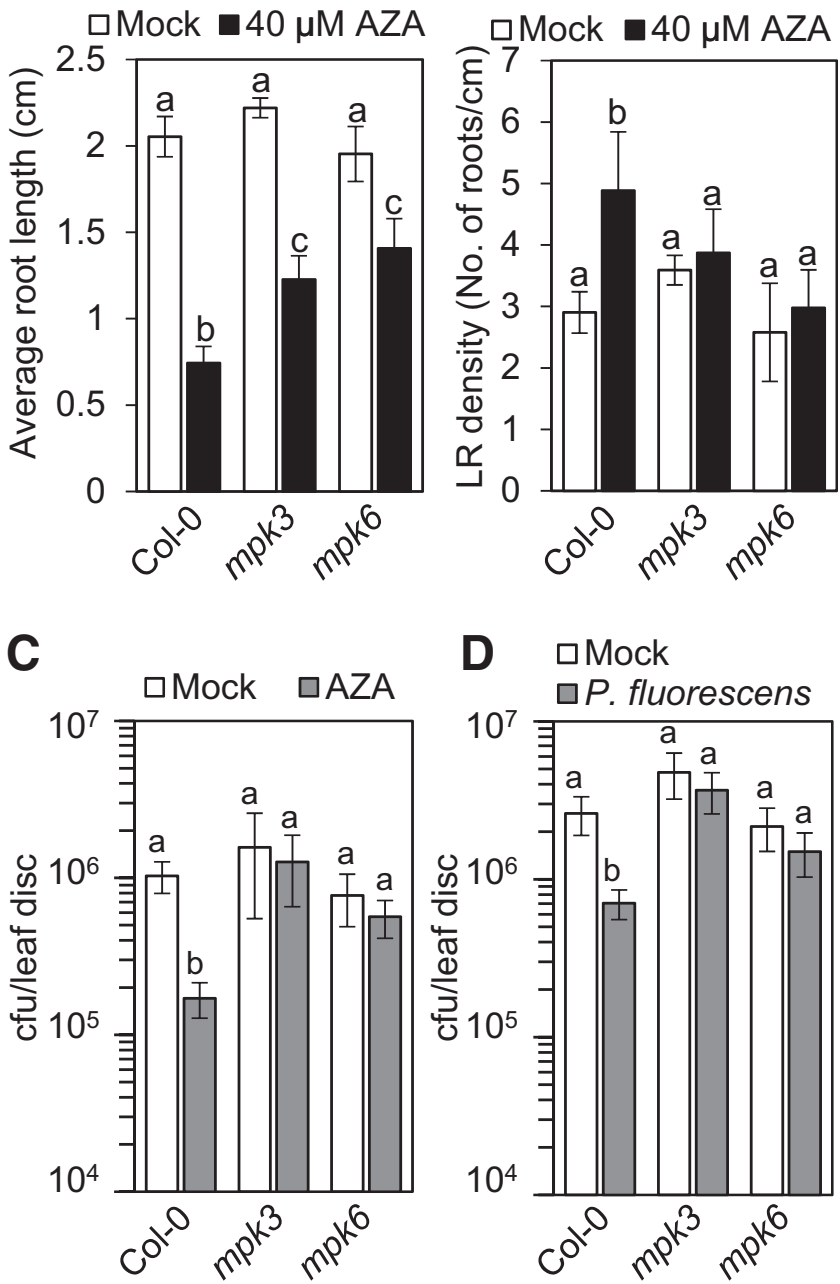

Fig. 4. $m p k$ mutants are compromised in root-mediated responses to azelaic acid (AZA). A, Average root length and B, lateral root (LR) density of 10day-old seedlings grown on solid one-half Murashige and Skoog agar media supplemented with $40 \mu \mathrm{m}$ AZA (in $5 \mathrm{mM}$ morpholineethane-sulfonic [MES] buffer, $\mathrm{pH}$ 5.7) or control MES (mock) in wild-type Columbia0 (WT Col-0), mpk3, and mpk6 plants. The average of root length or LR density \pm standard error from three independent experiments (each one with eight to 10 biological replicates) is shown. $\mathbf{C}$ and $\mathbf{D}$, Growth of the virulent bacteria PmaDG3 on WT Col-0, mpk3, and mpk6 plants 3 days postinfection (optical density at $600 \mathrm{~nm}=0.0003$ ). PmaDG3 was infiltrated in leaves 1 day after root treatment with control $\mathrm{H}_{2} \mathrm{O}$ (mock) or AZA (in $\mathrm{H}_{2} \mathrm{O}$ ) (C); or after 15 days of mock (10 $\left.\mathrm{mM} \mathrm{MgSO}_{4}\right)$ or Pseudomonas fluorescens root inoculation (D). The average number of colony-forming units per leaf disc \pm standard error from three independent experiments (each one with eight biological replicates) is shown. Graph $y$ axes are in $\log _{10}$ scale. Plants were grown in peat pellets. Different letters indicate statistically significant differences $(P<0.01$, analysis of variance, post hoc Tukey's honestly significant difference test). systemic resistance programs and priming establishment. We also observed that AZA applied to roots does not move upward to aerial tissue. One idea is that AZA applied to roots might induce the generation or facilitate the movement of related molecules capable of translocating from roots and triggering systemic resistance. Considering these and our previous results, we propose that the oxylipin AZA (and AZA signaling) is an important and general factor functioning in multiple systemic plant immunity programs.

AZA can induce systemic resistance and priming of the SAR-associated PR1 defense protein when applied to leaves (Balmer et al. 2015; Conrath et al. 2015; Jung et al. 2009). However, when root-applied, AZA is capable of inducing systemic resistance independently of PR1 priming. Moreover, LOX2, an ISR priming target protein (Conrath et al. 2006; Pozo et al. 2008), is not primed either. These findings indicate that additional systemic defense and priming targets in leaves may exist for root-applied AZA. A different primed factor is probably explained by the finding that AZA does not accumulate systemically, when applied to roots, compared with what was described in leaves (Jung et al. 2009). As discussed above, there may be one or more 'new' AZA-derived systemic signals generated in roots. Since pathogen resistance resulting from AZA application to roots requires the LTP-family proteins AZI1 and EARLI1, it is probable that such putative systemic root signals are lipidic in nature. If this is the case, its movement to or generation in aerial tissues might also depend on AZI1 or EARLI1 LTPs, as was observed for AZA in leaves (Cecchini et al. 2015). Because a pool of AZI1 is plastid-localized, it is possible that these signals could be related to AZA or precursors of oxylipins that are generated in plastid envelopes (Mukhtarova et al. 2011; Zoeller et al. 2012). An alternative possibility is that AZA applied to roots causes induction of a directly antimicrobial product that is translocated to leaves.

Diverse oxylipins can induce defenses (Blée 2002; Prost et al. 2005). Interestingly, many of these molecules can also induce root developmental changes (Vellosillo et al. 2007). This suggests that the developmental effects of oxylipins on roots could be related to defense signaling. ISR-inducing and other plant growth-promoting rhizobacteria (PGPR) and fungi usually induce root architectural changes upon colonization. Moreover, these developmental changes are very similar to those generated by AZA root treatment, loss of apical dominance, abundant lateral root formation, or both (ContrerasCornejo et al. 2009; Ortiz-Castro et al. 2011; Spaepen et al. 2014; Zamioudis et al. 2013). Although this root phenotype induced by beneficial microbes is believed to be related to the promotion of plant growth, it is not known how root architecture changes relate to the induction of systemic resistance to pathogens (Pieterse et al. 2014). One possibility is that auxinsignaling balances growth and systemic immunity (Stringlis et al. 2018). Here, we found that the same signaling molecule (AZA) activates both phenotypes. It is possible that oxylipins that act via AZI1 and EARLI1 are implicated in PGPR responses, connecting growth and systemic defense. Consistent with this, inoculation with the PGPR Azospirillum brasilense upregulates the root expression of $A Z I 1$ and induces growth inhibition (Spaepen et al. 2014). Moreover, this root arrest is diminished in azil mutant plants (Bouain et al. 2018). Future experiments in which oxylipin profiles are compared during ISR and other root-biotic interactions may shed light on this hypothesis. We also note that distinct AZA concentrations confer the growth and defense phenotypes. It is possible that, although the developmental and resistance signaling pathways share components (i.e., AZI1 and EARLI1), they can have differential sensitivities or threshold responses to AZA. However, the higher concentration needed for disease resistance may be due to the 
technical limitation of adding AZA to peat pots that may make some of the AZA unavailable to be taken up by the roots.

MPK3 and MPK6 are important components that contribute to SAR in leaves (Beckers et al. 2009). These kinases contribute

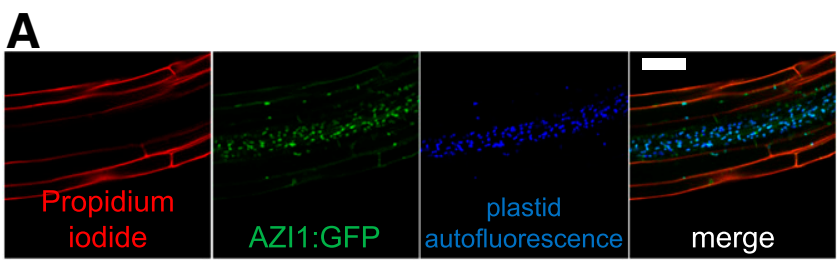

B
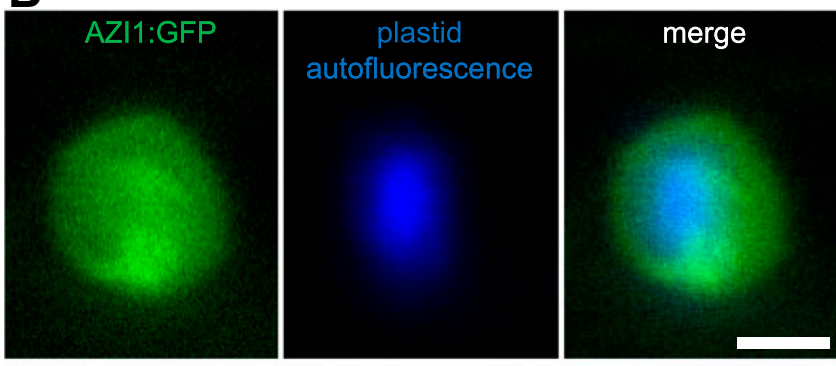

C

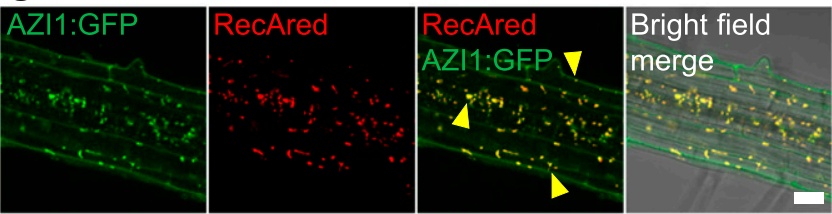

D
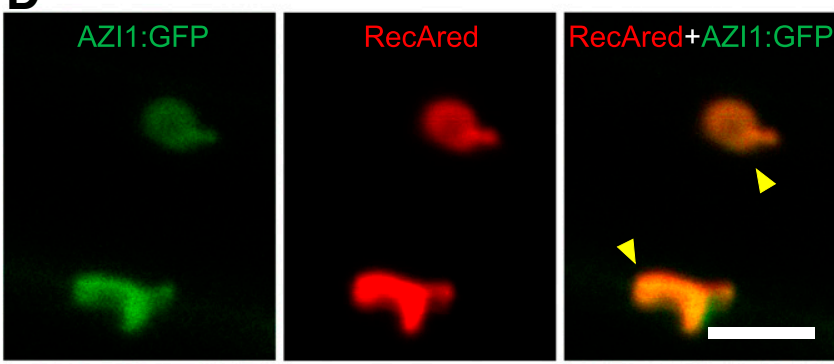

$\mathbf{E}$
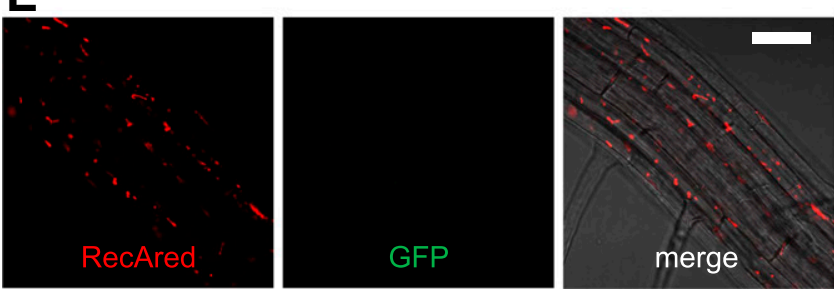

Fig. 5. AZI1 root-subcellular localization in Arabidopsis. Confocal micrographs of root elongation zones of 6-day-old dexamethasone (dex)-inducible AZI1:GFP (green fluorescent protein) seedlings grown on solid one-half Murashige and Skoog agar media. A, Localization of dex-inducible AZI1:GFP in Arabidopsis roots stained with propidium iodine to visualize the cell walls. Note the localization of a pool of AZI1:GFP at cell peripheries (red) as well as with autofluorescent plastids (in blue). B, Root plastid autofluorescence surrounded by GFP signal from AZI1:GFP. C, Colocalization of AZI1:GFP and plastid-marker:RFP (RecAred). D, Close up view of root plastid RecAred colocalization with AZI1:GFP in dexinducible AZI1:GFP seedlings. E, Localization of plastid-marker:RFP (RecAred). Note the lack of signal in the GFP channel in the middle panel, indicating that the RecAred signal did not bleed into the GFP channel. Yellow arrowheads indicate plastid colocalization between GFP fluorescence and RFP; plastid autofluorescence, blue; GFP, green; propidium and RFP, red. Scale bars in A and $\mathrm{E}=50 \mu \mathrm{m} ; \mathrm{B}=1.5 \mu \mathrm{m} ; \mathrm{C}=30 \mu \mathrm{m} ;$ and $\mathrm{D}=$ $5 \mu \mathrm{m}$. to AZA-induced root architecture changes, and they are also needed for aerial tissue disease resistance induced by treatment of roots with P. fluorescens. Notably, MPK3 and MPK6 have important defense roles in roots (Fujimoto et al. 2015; Sidonskaya et al. 2016). Because MPK3 regulates the abundance of AZI1 under abiotic stress conditions (Pitzschke et al. 2014), one possibility is that the requirement of these MPKs for systemic resistance induction is explained by their regulation of AZI1 and AZI1 LTP-family proteins, such as EARLI1. In support of this, both azil-1 and mpk3 mutant plants show slight intolerance to salt stress. Moreover, the salt-stress phenotype of $m p k 3$ is partially rescued by overexpression of AZI1, suggesting these proteins may act in the same process or processes (Pitzschke et al. 2014). MPK3 and MPK6 become activated in response to reactive oxygen species (ROS) (Asai et al. 2002; Jalmi and Sinha 2015; Kovtun et al. 2000) and upon plastid calcium release during basal defenses (Guo et al. 2016). Because AZA is generated by plastidic ROS increases (Zoeller et al. 2012), this raises the possibility that MPKs, AZI1-family LTPs, and AZA (or other plastid oxylipins) are regulated and act in concert when root defense responses are triggered.

Although we did not find AZA accumulating in leaves after root application, AZA can move to the roots when applied to leaves (Cecchini et al. 2015). Thus, it is possible that the AZA produced in aerial tissue when systemic resistance is triggered moves to the underground tissues. AZA in roots may induce other signals that, in turn, reinforce the aerial systemic immunity. This shoot-root-shoot loop in plant defense was previously suggested for other oxylipins (Agut et al. 2016; Erb et al. 2009; Groen 2016; Nalam et al. 2012). Furthermore, root stresses might control the activation state of MPK3 and MPK6, resulting in AZI1 or oxylipin signaling regulation. If this is true, depending on root conditions, systemic defenses could be more or less reinforced depending on an integration of the environment. Remarkably, this idea is in agreement with the so-called Darwin 'root-brain' hypothesis (Baluška et al. 2009; Fragoso et al. 2014; Kutschera and Niklas 2009), which postulates that roots are the sensorial regulatory place where plants make 'decisions' that orchestrate aboveground processes.

\section{MATERIALS AND METHODS}

\section{Plants.}

Arabidopsis thaliana mutant plants azil-1, earli1-1, mpk3-1, mpk6-2, and lox2-1 were previously described (Glauser et al. 2009; Jung et al. 2009; Liu and Zhang 2004; Wang et al. 2007; $\mathrm{Xu}$ et al. 2011). The silenced LOX2 SALK-line CS3748 and its control line CS3749 (Bell et al. 1995) were obtained from the Arabidopsis Biological Resources Center (Ohio State University, Columbus, OH, U.S.A.). azil-1, earli1-1, mpk3-1, mpk6-2,

Table 1. Root uptake and transport of deuterium-labeled azelaic acid $\left({ }^{2} \mathrm{H}-\mathrm{AZA}\right)$ in wild-type Columbia-0 (Col-0), azil-1, and earli1-1 plants ${ }^{\mathrm{z}}$

\begin{tabular}{llcc}
\hline Tissue & Genotype & AZA (mean \pm SD) & ${ }^{2}$ H-AZA (mean \pm SD) \\
\hline Shoot & Col-0 & $0.21 \pm 0.027 \mathrm{a}$ & ND \\
& azil -1 & $0.21 \pm 0.028 \mathrm{a}$ & ND \\
\multirow{3}{*}{ Root } & earli1-1 & $0.16 \pm 0.011 \mathrm{a}$ & ND \\
& Col-0 & $6.96 \pm 2.68 \mathrm{~b}$ & $24.31 \pm 8.60 \mathrm{c}$ \\
& azil-1 & $7.14 \pm 2.23 \mathrm{~b}$ & $23.4 \pm 5.62 \mathrm{c}$ \\
& earli1-1 & $7.69 \pm 1.71 \mathrm{~b}$ & $20.11 \pm 4.24 \mathrm{c}$ \\
\hline
\end{tabular}

Amount (micrograms per gram of fresh weight) of AZA or ${ }^{2} \mathrm{H}-\mathrm{AZA}$ in shoot or root tissues 1 day after application of $1 \mathrm{mM}$ of ${ }^{2} \mathrm{H}$-AZA to roots of 14-day-old plants. Different letters indicate statistically significant differences relevant to the mean $(P<0.01$, analysis of variance, post hoc Tukey's honestly significant difference test). SD = standard error from six biological replicates (each one with approximately 20 seedlings); ND = not detected. 
and lox2-1 plants were in the Columbia-0 (Col-0) background, while CS3748 and CS3749 lines were in Col gl1. Transgenic plants expressing AZI1:GFP fusion protein under the control of dex-inducible promoter (in the azil-1 background) (dex-AZI1: GFP) was previously described (Cecchini et al. 2015). F1 plants from a cross of RecAred background (Col-0 plants expressing red fluorescence protein targeted to root plastids [Haswell and Meyerowitz 2006]) with dex-AZI1:GFP were used for colocalization analysis. For ISR and AZA-induced disease resistance assays, sterile seeds were stratified for 3 days at $4^{\circ} \mathrm{C}$, were grown in Jiffy-7 pellets (Jiffy Products International) under 12-h day and 12-h night conditions at 20 to $21^{\circ} \mathrm{C}, 200$ to $230 \mu \mathrm{mol} \mathrm{s}{ }^{-1} \mathrm{~m}^{-2}$ light at rosette level, 50 to $70 \%$ relative humidity, and bottom watered with sterile water two times per week (Cecchini et al. 2015; Haney et al. 2015). For localization and AZA effects on root architecture, sterile seeds were stratified for 2 days at $4^{\circ} \mathrm{C}$, were germinated and grown in one-half Murashige and Skoog (MS) media (SigmaAldrich) (1\% sucrose) agar plates in a growth chamber with 16-h light $\left(120 \mu \mathrm{mol} \mathrm{s}^{-1} \mathrm{~m}^{-2}\right)$ and 8 -h dark cycles at $21^{\circ} \mathrm{C}$.

\section{AZA treatment of seedlings on plate assays.}

Seeds were germinated and were grown on one-half MS (1\% sucrose) agar plates supplemented with $40 \mu \mathrm{M}$ of AZA $\left(\mathrm{C}_{9} \mathrm{H}_{16} \mathrm{O}_{4}\right.$, molecular weight [MW] 188.22 [Sigma-Aldrich]), $40 \mu \mathrm{M}$ of suberic acid $\left(\mathrm{C} 8 ; \mathrm{C}_{8} \mathrm{H}_{14} \mathrm{O}_{4}, \mathrm{MW} 174.2\right.$ [SigmaAldrich], prepared in $5 \mathrm{mM}$ 2-[N-morpholino]ethane-sulfonic acid [MES] buffer, $\mathrm{pH}$ 5.7) or an appropriate volume of MES as mock-control. A 10-mM stock solution of AZA and C8 were prepared in $5 \mathrm{mM}$ MES buffer, $\mathrm{pH}$ 5.7. The plates were placed vertically into a plant growth chamber. Ten to 12 days after germination, the plates were photographed, using a Canon Power Shot A590 digital camera. Root lengths and lateral root numbers were analyzed using ImageJ.

For the assays in which the contact between aerial tissues and the agar media was avoided, 2-day-old seedlings were transferred to new MS plates with $18 \times 18 \mathrm{~mm}$ sterile glass coverslips placed on the media. Seedling cotyledons and hypocotyl were then isolated from the agar by being gently placed on top of the coverslips with only the roots in contact with the media.

\section{${ }^{\mathbf{2}}$ H-AZA root uptake and movement quantification.}

Arabidopsis seeds were germinated and were grown for 14 days on an approximately $60 \mathrm{~mm}$ diameter disk mesh (0.375 mm mesh; McMaster-Carr), placed onto 0.4\% agarose one-half MS (1\% sucrose) in 80 -ml beakers in sterile conditions. The mesh was then transferred, together with the seedlings, to $50 \times 9 \mathrm{~mm}$ plates containing a solution of $1 \mathrm{mM}$ ${ }^{2} \mathrm{H}$-AZA (MW 202.31, Medical Isotopes Inc.) prepared in $5 \mathrm{mM}$ MES buffer ( $\mathrm{pH}$ 5.6). The mesh affixed to the plate borders permitted the roots but not the aerial tissues to be in contact with the solution. The plates were put inside a humid chamber and, after $24 \mathrm{~h}$, roots and aerial tissues were separately collected, weighed, and frozen for the metabolite extraction (Lisec et al. 2006). Extracts were derivatized and were subjected to gas chromatography mass spectrometry analysis to determine the concentration of labeled ${ }^{2} \mathrm{H}-\mathrm{AZA}$ and unlabeled AZA (Jung et al. 2009; Li et al. 2012; Tschaplinski et al. 2012). A synthetic sample of ONA (a gift from C. Castresana, Centro Nacional de Biotecnología-Consejo Superior de Investigaciones Científicas) was used as standard. For generation of the ONA fragmentation patterns, approximately $1 \mathrm{mg}$ was dissolved in $500 \mu \mathrm{l}$ of silylation-grade acetonitrile, followed by the addition of $500 \mu \mathrm{l} N$-methyl- $N$-trimethylsilyltrifluoroacetamide with $1 \%$ trimethylchlorosilane (Pierce Chemical Co.) and heated for $1 \mathrm{~h}$ at $70^{\circ} \mathrm{C}$, to generate trimethylsilyl derivatives. After $2 \mathrm{~h}, 0.1 \mu \mathrm{l}$ of derivatized ONA was injected into a 5975C inert XL gas chromatograph-mass spectrometer (Agilent Technologies Inc.) fitted with a Rtx-5MS with Integra-guard (5\% diphenyl/95\% dimethyl polysiloxane) $30 \mathrm{~m} \times 250 \times 0.25 \mu \mathrm{m}$ film thickness capillary column, with the operating conditions as previously described (Li et al. 2012; Tschaplinski et al. 2012).

\section{Systemic resistance assays by root application of dicarboxylic acids.}

Roots of 25 approximately 28-day-old plants in Jiffy-7 pellets were submerged for approximately $30 \mathrm{~s}$ in $1 \mathrm{mM}$ AZA, $1 \mathrm{mM}$ suberic acid, or mock $(0.13 \%$ methanol $)$ solutions. This procedure allows the treatment of the entire root system without the aerial tissues coming into contact with the solutions. AZA and suberic acid stock solutions $(750 \mathrm{mM})$ were prepared in methanol and were then diluted to a final concentration in sterile water. For these assays, a higher concentration of AZA was used compared with that used in plate assays, to ensure that sufficient AZA was available to be absorbed by the roots in case the Jiffy-7 pellet matrix absorbed some of the AZA.

To evaluate systemic resistance, leaves were syringeinoculated with virulent Pseudomonas cannabina pv. alisalensis (formerly called $P$. syringae pv. maculicola ES4326 [Bull et al. 2010]) carrying an empty vector (PmaDG3) (optical density at $600 \mathrm{~nm}\left[\mathrm{OD}_{600}\right]=0.0003$ ) (Guttman and Greenberg 2001) 1 day after root treatments. Growth was quantified by dilution-plating, using eight leaves from eight different plants 3 days after PmaDG3 inoculation.

To analyze possible priming of PR1 and LOX2 induction, leaves were inoculated with PmaDG3 $\left(\mathrm{OD}_{600}=0.01\right) 1$ day after root treatments, and protein samples were obtained at different times postinfection. At least three leaves from three different plants were used per timepoint. The same amount (weight) of each sample was extracted in loading buffer (125 mM Tris [pH 6.8], 20\% glycerol, 4\% sodium dodecyl sulfate [SDS], $5 \mathrm{M}$ urea, $0.01 \%$ bromophenol blue). For immunoblots, equal amounts of total proteins were separated by SDS-polyacrylamide gel electrophoresis. Primary antibodies used herein were against PR1 (Agrisera AS10 687, 1:2,500, validated by Agrisera), LOX-C (Arabidopsis LOX2) (Agrisera AS07 258, 1:25,000, validated herein). Secondary antirabbit antibody conjugated to horseradish peroxidase (Thermo Scientific) was used at 1:1,000. Band signals were detected by using SuperSignal West stable peroxidase (Thermo Scientific).

\section{ISR assays.}

ISR assays were done as previously described (Haney et al. 2015), with some modifications. Ten-day old seedlings were first inoculated (on the top surface of the Jiffy pot) with a 6-ml solution of $P$. fluorescens WCS417r to a final $\mathrm{OD}_{600}$ of 0.01 $\left(10^{5} \mathrm{CFU} / \mathrm{ml}\right)$. Then, the entire pots were submerged for approximately $30 \mathrm{~s}$ in the same solution, without allowing contact of bacteria with the leaves. To evaluate the systemic resistance, 15 days after root-system inoculations, leaves five and six were syringe-infiltrated with PmaDG3 $\left(\mathrm{OD}_{600}=0.0003\right)$. Growth was quantified by dilution plating, using eight leaves from different plants 3 days after PmaDG3 inoculation.

\section{Confocal microscopy.}

Five-day-old transgenic Arabidopsis seedlings expressing AZI1:GFP under the dex-inducible promoter (Cecchini et al. 2015) or expressing both AZI1:GFP and RecAred were transferred to new plates containing $30 \mu \mathrm{M}$ dex. After $24 \mathrm{~h}$, seedlings were mounted in water or a $40-\mu \mathrm{g} / \mathrm{ml}$ PI solution (to stain cell walls) and were imaged using an upright Zeiss LSM710 laser-scanning confocal microscope (Zeiss). The 488-nm laser was used for GFP fluorescence (emission: 505 to $530 \mathrm{~nm}$ ), while the 535-nm laser was used for PI and RFP fluorescence (emission: 570 to $620 \mathrm{~nm}$ ) and the 633-nm laser for plastid 
autofluorescence (emission: 650 to $750 \mathrm{~nm}$ ). Images were taken using a LD C-Apochromat $40 \times / 1.1 \mathrm{~W}$ Korr objective. Sequential acquisition mode was used for acquisition of fluorescence. Images were processed using ImageJ (National Institutes of Health), ZEN 2012 (Zeiss), and Adobe Photoshop software.

\section{ACKNOWLEDGMENTS}

We thank S. C. Jiang and J. Jelenska for helpful discussions. We thank C. Castresana for the kind gift of synthetic ONA.

\section{LITERATURE CITED}

Agut, B., Gamir, J., Jaques, J. A., and Flors, V. 2016. Systemic resistance in citrus to Tetranychus urticae induced by conspecifics is transmitted by grafting and mediated by mobile amino acids. J. Exp. Bot. 67: 5711-5723.

Asai, T., Tena, G., Plotnikova, J., Willmann, M. R., Chiu, W.-L., GomezGomez, L., Boller, T., Ausubel, F. M., and Sheen, J. 2002. MAP kinase signalling cascade in Arabidopsis innate immunity. Nature 415:977-983.

Balmer, A., Pastor, V., Gamir, J., Flors, V., and Mauch-Mani, B. 2015. The 'prime-ome': Towards a holistic approach to priming. Trends Plant Sci. 20:443-452.

Baluška, F., Mancuso, S., Volkmann, D., and Barlow, P. W. 2009. The 'rootbrain' hypothesis of Charles and Francis Darwin: Revival after more than 125 years. Plant Signal. Behav. 4:1121-1127.

Beckers, G. J. M., Jaskiewicz, M., Liu, Y., Underwood, W. R., He, S. Y., Zhang, S., and Conrath, U. 2009. Mitogen-activated protein kinases 3 and 6 are required for full priming of stress responses in Arabidopsis thaliana. Plant Cell 21:944-953.

Bell, E., Creelman, R. A., and Mullet, J. E. 1995. A chloroplast lipoxygenase is required for wound-induced jasmonic acid accumulation in Arabidopsis. Proc. Natl. Acad. Sci. U.S.A. 92:8675-8679.

Blée, E. 2002. Impact of phyto-oxylipins in plant defense. Trends Plant Sci. 7:315-322.

Bouain, N., Satbhai, S. B., Korte, A., Saenchai, C., Desbrosses, G., Berthomieu, P., Busch, W., and Rouached, H. 2018. Natural allelic variation of the $A Z I 1$ gene controls root growth under zinc-limiting condition. PLoS Genet. 14:e1007304.

Bull, C. T., Manceau, C., Lydon, J., Kong, H., Vinatzer, B. A., and FischerLe Saux, M. 2010. Pseudomonas cannabina pv. cannabina pv. nov., and Pseudomonas cannabina pv. alisalensis (Cintas Koike and Bull, 2000) comb. nov., are members of the emended species Pseudomonas cannabina (ex Sutic \& Dowson 1959) Gardan, Shafik, Belouin, Brosch, Grimont \& Grimont 1999. Syst. Appl. Microbiol. 33:105-115.

Cecchini, N. M., Steffes, K., Schläppi, M. R., Gifford, A. N., and Greenberg, J. T. 2015. Arabidopsis AZI1 family proteins mediate signal mobilization for systemic defence priming. Nat. Commun. 6:7658.

Chanda, B., Xia, Y., Mandal, M. K., Yu, K., Sekine, K.-T., Gao, Q. M., Selote, D., Hu, Y., Stromberg, A., Navarre, D., Kachroo, A., and Kachroo, P. 2011. Glycerol-3-phosphate is a critical mobile inducer of systemic immunity in plants. Nat. Genet. 43:421-427.

Chaturvedi, R., Venables, B., Petros, R. A., Nalam, V., Li, M., Wang, X., Takemoto, L. J., and Shah, J. 2012. An abietane diterpenoid is a potent activator of systemic acquired resistance. Plant J. 71:161-172.

Chen, Y.-C., Holmes, E. C., Rajniak, J., Kim, J. G., Tang, S., Fischer, C. R., Mudgett, M. B., and Sattely, E. S. 2018. $N$-hydroxy-pipecolic acid is a mobile metabolite that induces systemic disease resistance in Arabidopsis. Proc. Natl. Acad. Sci. U.S.A. 115:E4920-E4929.

Conrath, U., Beckers, G. J. M., Flors, V., García-Agustín, P., Jakab, G., Mauch, F., Newman, M. A., Pieterse, C. M. J., Poinssot, B., Pozo, M. J., Pugin, A., Schaffrath, U., Ton, J., Wendehenne, D., Zimmerli, L., and Mauch-Mani, B.; Prime-A-Plant Group. 2006. Priming: Getting ready for battle. Mol. Plant-Microbe Interact 19:1062-1071.

Conrath, U., Beckers, G. J. M., Langenbach, C. J. G., and Jaskiewicz, M. R. 2015. Priming for enhanced defense. Annu. Rev. Phytopathol. 53: 97-119.

Constantino, N. N., Mastouri, F., Damarwinasis, R., Borrego, E. J., MoranDiez, M. E., Kenerley, C. M., Gao, X., and Kolomiets, M. V. 2013. Rootexpressed maize lipoxygenase 3 negatively regulates induced systemic resistance to Colletotrichum graminicola in shoots. Front. Plant Sci. 4: 510.

Contreras-Cornejo, H. A., Macías-Rodríguez, L., Cortés-Penagos, C., and López-Bucio, J. 2009. Trichoderma virens, a plant beneficial fungus, enhances biomass production and promotes lateral root growth through an auxin-dependent mechanism in Arabidopsis. Plant Physiol. 149: $1579-1592$

Erb, M., Lenk, C., Degenhardt, J., and Turlings, T. C. J. 2009. The underestimated role of roots in defense against leaf attackers. Trends Plant Sci. 14:653-659.

Fragoso, V., Rothe, E., Baldwin, I. T., and Kim, S.-G. 2014. Root jasmonic acid synthesis and perception regulate folivore-induced shoot metabolites and increase Nicotiana attenuata resistance. New Phytol. 202: 1335-1345

Fu, Z. Q., and Dong, X. 2013. Systemic acquired resistance: Turning local infection into global defense. Annu. Rev. Plant Biol. 64:839-863.

Fujimoto, T., Mizukubo, T., Abe, H., and Seo, S. 2015. Sclareol induces plant resistance to root-knot nematode partially through ethylenedependent enhancement of lignin accumulation. Mol. Plant-Microbe Interact 28:398-407.

Ghanem, M. E., Ghars, M. A., Frettinger, P., Pérez-Alfocea, F., Lutts, S., Wathelet, J. P., du Jardin, P., and Fauconnier, M. L. 2012. Organdependent oxylipin signature in leaves and roots of salinized tomato plants (Solanum lycopersicum). J. Plant Physiol. 169:1090-1101.

Glauser, G., Dubugnon, L., Mousavi, S. A. R., Rudaz, S., Wolfender, J.-L., and Farmer, E. E. 2009. Velocity estimates for signal propagation leading to systemic jasmonic acid accumulation in wounded Arabidopsis. J. Biol. Chem. 284:34506-34513.

Grebner, W., Stingl, N. E., Oenel, A., Mueller, M. J., and Berger, S. 2013. Lipoxygenase6-dependent oxylipin synthesis in roots is required for abiotic and biotic stress resistance of Arabidopsis. Plant Physiol. 161: 2159-2170.

Groen, S. C. 2016. Signalling in systemic plant defence-Roots put in hard graft. J. Exp. Bot. 67:5585-5587.

Guo, H., Feng, P., Chi, W., Sun, X., Xu, X., Li, Y., Ren, D., Lu, C., David Rochaix, J., Leister, D., and Zhang, L. 2016. Plastid-nucleus communication involves calcium-modulated MAPK signalling. Nat. Commun. 7:12173.

Guttman, D. S., and Greenberg, J. T. 2001. Functional analysis of the type III effectors AvrRpt2 and AvrRpm1 of Pseudomonas syringae with the use of a single-copy genomic integration system. Mol. Plant-Microbe Interact 14:145-155.

Haney, C. H., Samuel, B. S., Bush, J., and Ausubel, F. M. 2015. Associations with rhizosphere bacteria can confer an adaptive advantage to plants. Nat. Plants 1:15051.

Haswell, E. S., and Meyerowitz, E. M. 2006. MscS-like proteins control plastid size and shape in Arabidopsis thaliana. Curr. Biol. 16:1-11.

Hilker, M., Schwachtje, J., Baier, M., Balazadeh, S., Bäurle, I., Geiselhardt, S., Hincha, D. K., Kunze, R., Mueller-Roeber, B., Rillig, M. C., Rolff, J., Romeis, T., Schmülling, T., Steppuhn, A., van Dongen, J., Whitcomb, S. J., Wurst, S., Zuther, E., and Kopka, J. 2016. Priming and memory of stress responses in organisms lacking a nervous system. Biol. Rev. Camb. Philos. Soc. 91:1118-1133.

Hruz, T., Laule, O., Szabo, G., Wessendorp, F., Bleuler, S., Oertle, L., Widmayer, P., Gruissem, W., and Zimmermann, P. 2008. Genevestigator v3: A reference expression database for the meta-analysis of transcriptomes. Adv. Bioinforma. 2008:420747.

Jalmi, S. K., and Sinha, A. K. 2015. ROS mediated MAPK signaling in abiotic and biotic stress- striking similarities and differences. Front. Plant Sci. 6:769.

Jung, H. W., Tschaplinski, T. J., Wang, L., Glazebrook, J., and Greenberg, J. T. 2009. Priming in systemic plant immunity. Science 324:89-91

Kovtun, Y., Chiu, W. L., Tena, G., and Sheen, J. 2000. Functional analysis of oxidative stress-activated mitogen-activated protein kinase cascade in plants. Proc. Natl. Acad. Sci. U.S.A. 97:2940-2945.

Kutschera, U., and Niklas, K. J. 2009. Evolutionary plant physiology: Charles Darwin's forgotten synthesis. Naturwissenschaften 96:13391354.

León Morcillo, R. J., Ocampo, J. A., and García Garrido, J. M. 2012. Plant 9-lox oxylipin metabolism in response to arbuscular mycorrhiza. Plant Signal. Behav. 7:1584-1588.

Li, Y., Tschaplinski, T. J., Engle, N. L., Hamilton, C. Y., Rodriguez, M., Jr., Liao, J. C., Schadt, C. W., Guss, A. M., Yang, Y., and Graham, D. E. 2012. Combined inactivation of the Clostridium cellulolyticum lactate and malate dehydrogenase genes substantially increases ethanol yield from cellulose and switchgrass fermentations. Biotechnol. Biofuels 5:2.

Lim, G.-H., Shine, M. B., de Lorenzo, L., Yu, K., Cui, W., Navarre, D., Hunt, A. G., Lee, J.-Y., Kachroo, A., and Kachroo, P. 2016. Plasmodesmata localizing proteins regulate transport and signaling during systemic acquired immunity in plants. Cell Host Microbe 19:541-549.

Lisec, J., Schauer, N., Kopka, J., Willmitzer, L., and Fernie, A. R. 2006. Gas chromatography mass spectrometry-based metabolite profiling in plants. Nat. Protoc. 1:387-396. 
Liu, Y., and Zhang, S. 2004. Phosphorylation of 1-aminocyclopropane-1carboxylic acid synthase by MPK6, a stress-responsive mitogenactivated protein kinase, induces ethylene biosynthesis in Arabidopsis. Plant Cell 16:3386-3399.

Martinez-Medina, A., Flors, V., Heil, M., Mauch-Mani, B., Pieterse, C. M. J., Pozo, M. J., Ton, J., van Dam, N. M., and Conrath, U. 2016. Recognizing Plant Defense Priming. Trends Plant Sci. 21:818-822.

Mishina, T. E., and Zeier, J. 2007. Pathogen-associated molecular pattern recognition rather than development of tissue necrosis contributes to bacterial induction of systemic acquired resistance in Arabidopsis. Plant J. 50:500-513.

Mukhtarova, L. S., Mukhitova, F. K., Gogolev, Y. V., and Grechkin, A. N. 2011. Hydroperoxide lyase cascade in pea seedlings: Non-volatile oxylipins and their age and stress dependent alterations. Phytochemistry 72:356-364.

Nalam, V. J., Keereetaweep, J., and Shah, J. 2013. The green peach aphid, Myzus persicae, acquires a LIPOXYGENASE5-derived oxylipin from Arabidopsis thaliana, which promotes colonization of the host plant. Plant Signal. Behav. 8:e22735.

Nalam, V. J., Keeretaweep, J., Sarowar, S., and Shah, J. 2012. Root-derived oxylipins promote green peach aphid performance on Arabidopsis foliage. Plant Cell 24:1643-1653.

Nandi, A., Welti, R., and Shah, J. 2004. The Arabidopsis thaliana dihydroxyacetone phosphate reductase gene SUPPRESSSOR OF FATTY ACID DESATURASE DEFICIENCY1 is required for glycerolipid metabolism and for the activation of systemic acquired resistance. Plant Cell 16:465-477.

Návarová, H., Bernsdorff, F., Döring, A.-C., and Zeier, J. 2012. Pipecolic acid, an endogenous mediator of defense amplification and priming, is a critical regulator of inducible plant immunity. Plant Cell 24:5123-5141.

Ortiz-Castro, R., Díaz-Pérez, C., Martínez-Trujillo, M., del Río, R. E. Campos-García, J., and López-Bucio, J. 2011. Transkingdom signaling based on bacterial cyclodipeptides with auxin activity in plants. Proc. Natl. Acad. Sci. U.S.A. 108:7253-7258.

Park, S.-W. S.-W., Kaimoyo, E., Kumar, D., Mosher, S., and Klessig, D. F. 2007. Methyl salicylate is a critical mobile signal for plant systemic acquired resistance. Science 318:113-116.

Parker, J. E. 2009. The quest for long-distance signals in plant systemic immunity. Sci. Signal. 2:pe31.

Pieterse, C. M., van Wees, S. C., Hoffland, E., van Pelt, J. A., and van Loon, L. C. 1996. Systemic resistance in Arabidopsis induced by biocontrol bacteria is independent of salicylic acid accumulation and pathogenesisrelated gene expression. Plant Cell 8:1225-1237.

Pieterse, C. M. J., Zamioudis, C., Berendsen, R. L., Weller, D. M., Van Wees, S. C. M., and Bakker, P. A. 2014. Induced systemic resistance by beneficial microbes. Annu. Rev. Phytopathol. 52:347-375.

Pitzschke, A., Datta, S., and Persak, H. 2014. Salt stress in Arabidopsis: Lipid transfer protein AZI1 and its control by mitogen-activated protein kinase MPK3. Mol. Plant 7:722-738.

Pozo, M. J., Van Der Ent, S., Van Loon, L. C., and Pieterse, C. M. J. 2008. Transcription factor MYC2 is involved in priming for enhanced defense during rhizobacteria-induced systemic resistance in Arabidopsis thaliana. New Phytol. 180:511-523.

Prost, I., Dhondt, S., Rothe, G., Vicente, J., Rodriguez, M. J., Kift, N., Carbonne, F., Griffiths, G., Esquerré-Tugayé, M.-T., Rosahl, S., Castresana, C., Hamberg, M., and Fournier, J. 2005. Evaluation of the antimicrobial activities of plant oxylipins supports their involvement in defense against pathogens. Plant Physiol. 139:1902-1913.

Riedlmeier, M., Ghirardo, A., Wenig, M., Knappe, C., Koch, K., Georgii, E., Dey, S., Parker, J. E., Schnitzler, J.-P., and Vlot, A. C. 2017. Monoterpenes support systemic acquired resistance within and between plants. Plant Cell 29:1440-1459.
Shah, J. 2009. Plants under attack: Systemic signals in defence. Curr. Opin. Plant Biol. 12:459-464.

Sidonskaya, E., Schweighofer, A., Shubchynskyy, V., Kammerhofer, N., Hofmann, J., Wieczorek, K., and Meskiene, I. 2016. Plant resistance against the parasitic nematode Heterodera schachtii is mediated by MPK3 and MPK6 kinases, which are controlled by the MAPK phosphatase AP2C1 in Arabidopsis. J. Exp. Bot. 67:107-118.

Spaepen, S., Bossuyt, S., Engelen, K., Marchal, K., and Vanderleyden, J. 2014. Phenotypical and molecular responses of Arabidopsis thaliana roots as a result of inoculation with the auxin-producing bacterium Azospirillum brasilense. New Phytol. 201:850-861.

Spoel, S. H., and Dong, X. 2012. How do plants achieve immunity? Defence without specialized immune cells. Nat. Rev. Immunol. 12: 89-100.

Stringlis, I. A., Proietti, S., Hickman, R., Van Verk, M. C., Zamioudis, C. and Pieterse, C. M. J. 2018. Root transcriptional dynamics induced by beneficial rhizobacteria and microbial immune elicitors reveal signatures of adaptation to mutualists. Plant J. 93:166-180.

Truman, W., Bennett, M. H., Kubigsteltig, I., Turnbull, C., and Grant, M. 2007. Arabidopsis systemic immunity uses conserved defense signaling pathways and is mediated by jasmonates. Proc. Natl. Acad. Sci. U.S.A 104:1075-1080.

Tschaplinski, T. J., Standaert, R. F., Engle, N. L., Martin, M. Z., Sangha, A. K., Parks, J. M., Smith, J. C., Samuel, R., Jiang, N., Pu, Y., Ragauskas, A. J., Hamilton, C. Y., Fu, C., Wang, Z.-Y., Davison, B. H., Dixon, R. A., and Mielenz, J. R. 2012. Down-regulation of the caffeic acid $O$ methyltransferase gene in switchgrass reveals a novel monolignol analog. Biotechnol. Biofuels 5:71.

Vellosillo, T., Martínez, M., López, M. A., Vicente, J., Cascón, T., Dolan, L., Hamberg, M., and Castresana, C. 2007. Oxylipins produced by the 9 lipoxygenase pathway in Arabidopsis regulate lateral root development and defense responses through a specific signaling cascade. Plant Cell 19:831-846.

Vicente, J., Cascón, T., Vicedo, B., García-Agustín, P., Hamberg, M., and Castresana, C. 2012. Role of 9-lipoxygenase and $\alpha$-dioxygenase oxylipin pathways as modulators of local and systemic defense. Mol. Plant 5:914-928.

Wang, H., Ngwenyama, N., Liu, Y., Walker, J. C., and Zhang, S. 2007. Stomatal development and patterning are regulated by environmentally responsive mitogen-activated protein kinases in Arabidopsis. Plant Cell 19:63-73.

Wittek, F., Hoffmann, T., Kanawati, B., Bichlmeier, M., Knappe, C., Wenig, M., Schmitt-Kopplin, P., Parker, J. E., Schwab, W., and Vlot, A. C. 2014 Arabidopsis ENHANCED DISEASE SUSCEPTIBILITY1 promotes systemic acquired resistance via azelaic acid and its precursor 9-oxo nonanoic acid. J. Exp. Bot. 65:5919-5931.

Xu, D., Huang, X., Xu, Z.-Q., and Schläppi, M. 2011. The HyPRP gene EARLII has an auxiliary role for germinability and early seedling development under low temperature and salt stress conditions in Arabidopsis thaliana. Planta 234:565-577.

Yu, K., Soares, J. M., Mandal, M. K., Wang, C., Chanda, B., Gifford, A. N., Fowler, J. S., Navarre, D., Kachroo, A., and Kachroo, P. 2013. A feedback regulatory loop between G3P and lipid transfer proteins DIR1 and AZI1 mediates azelaic-acid-induced systemic immunity. Cell Reports 3:1266-1278.

Zamioudis, C., Mastranesti, P., Dhonukshe, P., Blilou, I., and Pieterse, C. M. J. 2013. Unraveling root developmental programs initiated by beneficial Pseudomonas spp. bacteria. Plant Physiol. 162:304-318.

Zoeller, M., Stingl, N., Krischke, M., Fekete, A., Waller, F., Berger, S., and Mueller, M. J. 2012. Lipid profiling of the Arabidopsis hypersensitive response reveals specific lipid peroxidation and fragmentation processes: Biogenesis of pimelic and azelaic acid. Plant Physiol. 160: 365-378. 